\title{
Ex vivo anti-microbial efficacy of various formaldehyde releasers against antibiotic resistant and antibiotic sensitive microorganisms involved in infectious keratitis
}

Daeryl E. Amponin ${ }^{1}$, Joanna Przybek-Skrzypecka ${ }^{2,3}$, Mariya Zyablitskaya ${ }^{1}$, Anna Takaoka ${ }^{1}$, Leejee H. Suh', Takayuki Nagasaki ${ }^{1}$, Stephen L. Trokel ${ }^{1}$ and David C. Paik ${ }^{1 *}$ (1)

\begin{abstract}
Background: Corneal infections with antibiotic-resistant microorganisms are an increasingly difficult management challenge and chemically or photochemically cross-linking the cornea for therapy presents a unique approach to managing such infections since both direct microbial pathogens killing and matrix stabilization can occur simultaneously. The present study was undertaken in order to compare the anti-microbial efficacy, in vitro, of 5 candidate cross-linking solutions against 5 different microbial pathogens with relevance to infectious keratitis.

Methods: In vitro bactericidal efficacy studies were carried out using 5 different FARs [diazolidinyl urea (DAU), 1,3bis(hydroxymethyl)-5,5-dimethylimidazolidine-2,4-dione (DMDM), sodium hydroxymethylglycinate (SMG), 2(hydroxymethyl)-2-nitro-1,3-propanediol (NT = nitrotriol), 2-nitro-1-propanol (NP)] against 5 different microbial pathogens including two antibiotic-resistant species [methicillin-sensitive Staphylococcus aureus (MSSA), methicillinresistant Staphylococcus aureus (MRSA), vancomycin-resistant Enterococcus (VRE), Pseudomonas aeruginosa (PA), and Candida albicans (CA)]. Standard in vitro antimicrobial testing methods were used.

Results: The results for MSSA were similar to those for MRSA. DAU, DMDM, and SMG all showed effectiveness with greater effects generally observed with longer incubation times and higher concentrations. Against MRSA, $40 \mathrm{mM}$ SMG at 120 min showed a > 95\% kill rate, $p<0.02$. Against VRE, $40 \mathrm{mM}$ DAU for 120 min showed a $>94 \%$ kill rate, $p<0.001$. All FARs showed bactericidal effect against Pseudomonas aeruginosa, making PA the most susceptible of the strains tested. Candida showed relative resistance to these compounds, requiring high concentrations (100 mM) to achieve kill rates greater than $50 \%$.
\end{abstract}

Conclusion: Our results show that each FAR compound has different effects against different cultures. Our antimicrobial armamentarium could potentially be broadened by DAU, DMDM, SMG and other FARs for antibioticresistant keratitis. Further testing in live animal models are indicated.

Keywords: Sodium hydroxymethylglycinate, Tissue cross-linking, Infectious keratitis, Methicillin-resistant Staphylococcus aureus (MRSA), Antibiotic resistant microorganisms, Formaldehyde releasers (FARs)

\footnotetext{
* Correspondence: dcp14@cumc.columbia.edu

${ }^{1}$ Department of Ophthalmology, Edward S. Harkness Eye Institute, Columbia

University College of Physicians and Surgeons, 635 West 165th Street,

Research Annex Room 715, New York, NY 10032, USA

Full list of author information is available at the end of the article
}

(c) The Author(s). 2020 Open Access This article is distributed under the terms of the Creative Commons Attribution 4.0 International License (http://creativecommons.org/licenses/by/4.0/), which permits unrestricted use, distribution, and reproduction in any medium, provided you give appropriate credit to the original author(s) and the source, provide a link to the Creative Commons license, and indicate if changes were made. The Creative Commons Public Domain Dedication waiver (http://creativecommons.org/publicdomain/zero/1.0/) applies to the data made available in this article, unless otherwise stated. 


\section{Background}

Corneal scars, remnants of infectious keratitis, are one of the leading causes of blindness and visual impairment worldwide [1] and a continuous rise in the incidence of bacterial and fungal keratitis has been reported recently [2]. The US Centers for Disease Control and Prevention estimates that over 2 million people are infected with drug-resistant microbes annually in the US [3, 4]. This includes a soaring number of multi-resistant microorganisms affecting the human cornea (i.e. Pseudomonas aeruginosa (PA), methicillin- resistant Staphylococcus aureus (MRSA) and methicillin-susceptible Staphylococcus aureus (MSSA)) [5, 6]. Rising rates of resistance to first and second-line traditional antibiotic treatment, such as the fluoroquinolone ciprofloxacin, has been observed [7]. Thus, the number of blind individuals as a result of corneal infections will rise as our ability to effectively treat infectious keratitis diminishes secondary to the increasing development of microbial pathogen resistance. This underlines a need to seek alternatives to available antibiotic treatment protocols [8].

Several strategies to combat multi-drug resistance are under development. Some of the approaches include: the development of new classes of antibiotics (i.e. teixobactin, which shows activity against Staphylococcus aureus and Mycobacterium tuberculosis) [9], novel application of wellknown antibiotic (i.e. chloramphenicol for fungal infection [10]), synergistic combinations of existing antibiotics [11], systemic antibiotics [12], as well as potentiator molecules (especially for gram negative bacteria) that serve to increase bacterial membrane permeability [13]. One of the potentially new approaches to multi-drug resistant keratitis treatment is riboflavin-UVA photochemical corneal cross-linking (or CXL). CXL was originally developed for the treatment of keratoconus [14]. Covalent modification of fibrillar collagens and the extracellular matrix molecules results in tissue strengthening and can halt ectatic progression [15] . A growing body of evidence shows the benefits of PACK-CXL, a trademark for application of the CXL techniques to infectious keratitis [16].

Importantly, PACK-CXL has been shown to have equal or improved bactericidal efficacy against antibiotic resistant strains of Pseudomonas, Enterococcus, and Staphylococcus aureus [17]. Furthermore, an overwhelming number of reports have shown that CXL is effective as an adjunct to standard antibiotic agents $[18,19]$ for bacterial keratitis. CXL has also been used with success as a primary therapy for infectious keratitis due to bacterial causes [20, 21]. That being said, it is important to note that CXL is contraindicated for the treatment of herpetic keratitis [22] and can cause reactivation of latent herpes [23]. CXL also appears to be less effective against fungal infections, where the PACK-CXL clinical literature is less convincing [24]. Other drawbacks to
CXL include the potential UVA exposure risks and issues surrounding corneal epithelial debridement. For these reasons, we are investigating the use of topical therapeutic cross-linking solutions to provide a new cross-linking option for patients.

Formaldehyde releasers (FARs) are a group of over 60 chemicals widely used in the textile and cosmetics industries [25]. They differ from one another in terms of toxicity, water solubility, molecular weight, hydrophobicity, mutagenicity and bioavailability [25]. We are developing them for clinical ophthalmic use in the form of a cross-linking solution. This could provide a new option for corneal tissue stabilization in keratoconus and post -LASIK ectasias. Initial studies had focused on the nitroalcohols, a subgroup of FARs [26]. The aim of the present study was to assess the antimicrobial efficacy and identify differences between 5 selected formaldehyde-releasing agents: diazolidinyl urea (DAU), 1,3-bis(hydroxymethyl)-5,5-dimethylimidazolidine2,4-dione (DMDM), sodium hydroxymethylglycinate (SMG), 2-(hydroxymethyl)-2-nitro-1,3-propanediol (NT = nitrotriol), and 2-nitro-1-propanol (NP) [see Table 1] against 5 different keratitis pathogens. The present study serves as an extension of our previous work using SMG only [33]. Considering the interesting results from that study, we sought to look for other FARs with potential application as topical cross-linking agents for infectious keratitis.

\section{Methods \\ Chemicals}

The bactericidal effect of five different formaldehydereleasing agents were studied. Key chemicals were as follows: a) sodium hydroxymethylglycinate 50\% (SMG) [Suttocide $^{\mathrm{\tau m}}$, Ashland, Columbus OH, USA], b) 2-nitro-1propanol (NP), c) diazolidinyl urea (DAU) [Sigma Aldrich, Saint Louis, USA], d) 1,3-bis(hydroxymethyl)-5,5-dimethyl-2,4-imidazolidinedione (DMDM) and e) 2-(hydroxymethyl)-2-nitro-1,3-propanediol (NT) [Chemistry Connection LLC, Conway AR, USA]. BBL ${ }^{\mathrm{Tm}}$ Trypticase $^{\mathrm{TM}}$ Soy Broth, BBL ${ }^{\mathrm{TM}}$ Trypticase $^{\mathrm{TM}}$ Soy Agar, Difco ${ }^{\mathrm{Tm}}$ Sabouraud Dextrose Broth, Difco D/E Neutralizing Broth [Fisher Scientific, Waltham, MA, USA] were used for bacteria growth. Adult bovine serum albumin (BSA) was bought from Sigma-Aldrich Corp. (St. Louis, MO, USA). All FARs dilutions were made with balanced salt solution, BSS Plus ${ }^{\circ}$ [Alcon Laboratory Inc., Forth Worth, TX, USA] and were prepared within $60 \mathrm{~min}$ of the experiments apart from NT and NP which were prepared $24 \mathrm{~h}$ before the experiment due to their prolonged formaldehyde release.

\section{Bacteria strains}

The following microorganisms were obtained from the American Type Culture Collection (ATCC, Manassas, VA, USA): methicillin-resistant Staphylococcus aureus 
Table 1 Formaldehyde-releasing agents (FARs) included in the study, chemical names, acronyms, molecular weights and structure

\begin{tabular}{|c|c|c|c|c|c|c|}
\hline Chemical name & Acronym & $\begin{array}{l}\text { Moles of FA } \\
\text { released per } 1 \\
\text { mol of FAR }\end{array}$ & $\begin{array}{l}\text { Molecular } \\
\text { weight }\end{array}$ & $\begin{array}{l}\text { Predicted octanol/ } \\
\text { water partition } \\
\text { coefficient, LogP }\end{array}$ & $\begin{array}{l}\text { Toxicity } \\
\text { (LD50, } \\
\text { dermal, } \\
\text { rabbit) }\end{array}$ & Structure \\
\hline $\begin{array}{l}\text { Diazolidinyl urea (1-[3,4-bis(hydroxymethyl)- } \\
\text { 2,5-dioxoimidazolidin-4-yl]-1,3- } \\
\text { bis(hydroxymethyl)urea) }\end{array}$ & DAU & 4 & 278.22 & $-5.395 \pm 0.866[27]$ & $\begin{array}{l}>2000 \mathrm{mg} / \\
\mathrm{kg}[28]\end{array}$ & \\
\hline $\begin{array}{l}\text { 1,3-Bis(Hydroxymethyl)-5,5- } \\
\text { dimethylimidazolidine-2,4-dione }\end{array}$ & DMDM & 2 & 188.18 & $-2.3[29]$ & $\begin{array}{l}>2000 \mathrm{mg} / \\
\mathrm{kg}[30]\end{array}$ & \\
\hline Sodium hydroxymethylglycinate & SMG & 1 & 127.07 & $-1.197[31]$ & $\begin{array}{l}>2000 \mathrm{mg} / \\
\mathrm{kg}[32]\end{array}$ & \\
\hline 2-(hydroxymethyl)-2-nitro-1,3-propanediol & NT & 3 & 151.12 & $-0.115 \pm 0.77[27]$ & NA & \\
\hline 2-nitro-1-propanol & NP & 1 & 105.09 & $-0.066 \pm 0.269[27]$ & NA & \\
\hline Formaldehyde & FA & & 30.03 & $0.350 \pm 0.145[27]$ & NA & \\
\hline
\end{tabular}

[(MRSA) ATCC 33592], Staphylococcus aureus (ATCC 6538), Pseudomonas aeruginosa (ATCC 27853), Candida albicans (ATTC 11651). VRE was a clinical isolate \#10988 from Columbia University Medical Center, Department of Surgery.

\section{Experimental procedure}

Treatment conditions (FAR concentration, incubation period and use of NB) are summarized in Table 2. Pathogens were grown from a slant in either a Trypticase Soy Broth (TSB) with 10\% Albumin for MRSA, MSSA, PA, and VRE or a Difco Sabouraud Dextrose Broth (DB) with $10 \%$ BSA for CA. The optical density of each pathogen was determined using a spectrophotometer set at $600 \mathrm{~nm}$ and zeroed using respective broths containing 10\% BSA protein. From the exponential growth phase, $50 \mu \mathrm{L}$ of $5 \times$ $10^{3}$ to $10^{5}$ colony forming units (CFU) per mL were added to a 96 well flat bottom assay plate. Each well was treated with a final concentration of $20 \mathrm{mM}, 40 \mathrm{mM}, 100 \mathrm{mM}$ of FAR by pipetting $50 \mu \mathrm{L}$ of FAR dissolved in a balanced salt solution (BSS) into each well. Control wells were treated with $50 \mu \mathrm{L}$ of BSS. Following addition of FAR, the lid was placed on the assay plate, and it was gently rocked back and forth 5 times to mix the FAR and pathogen. After a 60-120 min treatment period, $200 \mu \mathrm{L}$ of Difco D/E Neutralizing Broth $(39 \mathrm{mg} / \mathrm{mL})$ was pipetted into each well to neutralize the SMG, and mixed by pipetting up and down five times. The resulting mixture of the pathogen, FAR, and neutralizing agent was pipetted onto an BBL trypticase soy agar plate and evenly spread with an L-spreader. Plates were incubated upside down in a Forma-Steri-Cycle $\mathrm{CO}_{2}$ incubator for 20-28 h, except Candida which was incubated for a longer time period $(48-58 \mathrm{~h})$ due to its slower growth rate. Plates were then manually counted by the naked eye and recorded. During the counting process, each colony was marked on the bottom of the culture plate with a fine point marking pen in order to assure accurate counting.

\section{Statistical analysis}

Each final concentration of FAR (0 [control], $20 \mathrm{mM}, 40$ $\mathrm{mM}, 100 \mathrm{mM}$ ) was tested on 3 to 6 plates for every

Table 2 Summary of the experimental conditions

\begin{tabular}{llll}
\hline Bacteria strain & FAR's concentration, mM & Time of incubation, min & Microorganism concentration, CFUs \\
\hline Methicillin-sensitive Staphylococcus aureus & $0,20,40,100$ & 60,120 & $10^{4}, 10^{4 / 2}$ \\
Methicillin-resistant Staphylococcus aureus & $0,20,40,100$ & 60,120 & $10^{4}, 10^{4 / 2}$ \\
Vancomycin-resistant Enterococcus & $0,20,40,100$ & 60,120 & $10^{4}, 10^{4 / 2}$ \\
Pseudomonas aeruginosa & $0,20,40,100$ & 60,120 & $10^{4}, 10^{4 / 2}$ \\
Candida albicans & $0,20,40,100$ & 60,120 & $10^{4}, 10^{4 / 2}$ \\
\hline
\end{tabular}


pathogen and every incubation time (30 min, $1 \mathrm{~h}, 2 \mathrm{~h}$ ). The kill rate for each plate was calculated by comparing the number of colonies on the plate and the mean value of the colonies on the control plates. Two-way ANOVA was used to compare the differences in the means of the kill rate, FARs concentration, and the time of the treatment. As for the graphs, the mean kill rate for every plate for each FAR dosage were plotted and a linear regression model was generated. Wilcoxon rank sum test was applied to compare two groups. For all of the analyses $p<0.05$ was considered statistically significant. The data and models were analyzed using the software STATA 13.1 (College Station, TX, USA). These computational statistical analyses were carried out with the assistance the Columbia University biostatistical core service.

\section{Results}

In this study, we tested the anti-microbial efficacy of five FARs against 5 different relevant pathogens and a main point of this study has been to delineate potential differences in efficacy between the different compounds. The effect of FARs differed among microorganisms and compounds and their concentrations itself. SMG proved to be the most effective overall. Compared to the control group the most prominent bactericidal effect for $60 \mathrm{~min}$ incubations were obtained for $100 \mathrm{mM}$ SMG against MRSA (kill rate 96\%, SD 5\%) and PA (kill rate 96\%, SD $3 \%)$. This is particularly important as these two species are particularly prevalent antibiotic resistant organisms. For VRE the best effect was obtained with DMDM 100 $\mathrm{mM}$ at $60 \mathrm{~min}$ (kill rate $91 \%$, SD 7\%). As would be expected based on the relationship between contact time and kill rate, using $120 \mathrm{~min}$ incubation time, the kill rate exceeded $90 \%$ in 11 different means (DAU $100 \mathrm{mM}$ and SMG $100 \mathrm{mM}$ for all bacteria tested: MRSA, MSSA, PA, VRE; DAU $40 \mathrm{mM}$ for VRE; SMG $40 \mathrm{mM}$ for MRSA and DMDM $100 \mathrm{mM}$ for PA) (Table 3). That being said, greater killing effects were not always observed by extending the exposure time from $60 \mathrm{~min}$ to $120 \mathrm{~min}$ for a given concentration. That is, when comparing kill rates between $60 \mathrm{~min}$ and $120 \mathrm{~min}$ at the same concentration. The reasons for this inconsistency is unclear, however, explanations include the possibility of polymerization effects occurring as a result of released free formaldehyde (i.e. formaldehyde polymerizing with itself) as well as possible reactions with the FAR products resulting in formation of either the starting material or additional reaction products. An example of this was reported previously by our group [26].

In general, the results with the nitroalcohols (NA) were not satisfactory. The two NAs tested, NT and NP demonstrated limited potential against MSSA, MRSA and VRE although both showed some effectiveness against PA at $60 \mathrm{~min}$ incubation. NAs tend to release free FA slowly by comparison with other FARs (unpublished data). This may account for the lack of antibacterial effectiveness shown by the NAs. Surprisingly, the NAs did fairly well against CA, an organism that proved to be troublesome for the other FARs tested. In summary, the FAR/pathogen pairings that showed the most consistent trends (that is, both dose and time dependency) were as follows: SMG against MSSA, MRSA, and PA; DAU against MRSA and VRE; DMDM against MRSA.

A description of results based on the organism tested is now included:

\section{Staphylococcus aureus (methicillin sensitive $=$ MSSA and methicillin resistant $=$ MRSA) (Fig. $1 \mathrm{a}$ and $\mathbf{b}$ and Table 3 )}

The results for MRSA and MSSA were similar for all the compounds. In other words, the effectiveness of a given FAR was similar against either MSSA or MRSA and this is to be expected, given that they are both Staphylococcus species. DAU, DMDM, and SMG all showed some effectiveness with greater effects observed with the longer incubation time of $120 \mathrm{~min}$. There was also a significant concentration dependency for these three agents with higher concentrations having greater efficacy than lower.

MSSA growth was inhibited in a dose-dependent pattern. The results obtained for DAU showed robust kill rate, mean colony count for $100 \mathrm{mM}$ was $14(\mathrm{SD} \pm 4.4$; $p<0001$ compared to control group), followed by mean 72 for $40 \mathrm{mM}$ concentration (SD \pm 27.6 ; $p<0.001$ compared to control group) and 120 for $20 \mathrm{mM}$ concentration ( $\mathrm{SD} \pm 50.2 ; p<0.001$ compared to control group). The kill rate for each compound and its concentration, as well as the statistical significance of their differences are summarized in Table 3.

Similar to MSSA, MRSA growth was inhibited in a dose-dependent manner using DAU, SMG, DMDM and NT in 60 min incubation time and for DAU, DMDM and SMG for $120 \mathrm{~min}$ incubation time. The mean kill rate for the $100 \mathrm{mM}$ dose was: 1 ) SMG at 96\% (SD $\pm 5 \%$ $p<0.0001$ compared to the controls), 2) DAU at $86 \%$ (SD $\pm 16 \%, p<0.0001$ versus control) and 3) DMDM at $80 \%$ ( $\mathrm{SD} \pm 12 \% p<0.0001$ vs controls) for 60 min exposure. Additionally, statistically significant results at $p<$ 0.01 were obtained for 22 different conditions using all 5 FARs at either 60- or 120-min exposures (Table 3). Figure $1 \mathrm{a}$ and $\mathrm{b}$ depicts mean kill rates of each compound tested.

\section{Enterococcus (vancomycin resistant $=$ VRE) (Fig. 1c and Table 3)}

For VRE, SMG and DAU were the most effective, with DAU showing time and concentration dependency with 
Table 3 60- and 120-min incubation time experiment: Mean Kill Rates \pm SD of different compounds on five different bacterial strains and $p$ values ( $p^{*}$ compares 0 and the relevant dose of the same FAR for 60 min, $p^{* *}$ compares 0 and the relevant dose of each FAR for $120 \mathrm{~min}$ )

\begin{tabular}{|c|c|c|c|c|c|c|}
\hline \multirow{2}{*}{$\begin{array}{l}\text { Bacteria } \\
\text { strain }\end{array}$} & \multirow[t]{2}{*}{ Compound } & \multirow{2}{*}{$\begin{array}{l}\text { Concentration } \\
(\mathrm{mM})\end{array}$} & \multicolumn{2}{|l|}{$60 \mathrm{~min}$} & \multicolumn{2}{|l|}{$120 \mathrm{~min}$} \\
\hline & & & Mean Kill Rate \pm SD (\%) & $p^{*}$ & Mean Kill Rate \pm SD (\%) & $p^{* *}$ \\
\hline \multirow[t]{15}{*}{ MSSA } & \multirow[t]{3}{*}{ DAU } & 20 & $64 \pm 13$ & 0.000 & $38 \pm 15$ & 0.239 \\
\hline & & 40 & $55 \pm 36$ & 0.000 & $80 \pm 10$ & 0.017 \\
\hline & & 100 & $92 \pm 6$ & 0.000 & $93 \pm 5$ & 0.006 \\
\hline & \multirow[t]{3}{*}{ DMDM } & 20 & $-2 \pm 77$ & 0.92 & $55 \pm 22$ & 0.091 \\
\hline & & 40 & $48 \pm 13$ & 0.01 & $49 \pm 30$ & 0.132 \\
\hline & & 100 & $52 \pm 48$ & 0.006 & $88 \pm 11$ & 0.010 \\
\hline & \multirow[t]{3}{*}{ SMG } & 20 & $35 \pm 16$ & 0.055 & $81 \pm 9$ & 0.016 \\
\hline & & 40 & $49 \pm 27$ & 0.009 & $87 \pm 10$ & 0.010 \\
\hline & & 100 & $88 \pm 2$ & 0.000 & $100 \pm 4$ & 0.004 \\
\hline & \multirow[t]{3}{*}{ NT } & 20 & $-20 \pm 14$ & 0.262 & $-48 \pm 31$ & 0.137 \\
\hline & & 40 & $57 \pm 36$ & 0.003 & $-47 \pm 108$ & 0.150 \\
\hline & & 100 & $52 \pm 47$ & 0.006 & $-60 \pm 115$ & 0.067 \\
\hline & \multirow[t]{3}{*}{ NP } & 20 & $39 \pm 9$ & 0.037 & $-66 \pm 47$ & 0.044 \\
\hline & & 40 & $38 \pm 46$ & 0.042 & $-61 \pm 123$ & 0.062 \\
\hline & & 100 & $39 \pm 24$ & 0.035 & $18 \pm 13$ & 0.565 \\
\hline \multirow[t]{15}{*}{ MRSA } & \multirow[t]{3}{*}{ DAU } & 20 & $27 \pm 29$ & 0.042 & $59 \pm 25$ & 0.119 \\
\hline & & 40 & $51 \pm 12$ & 0.000 & $94 \pm 4$ & 0.016 \\
\hline & & 100 & $86 \pm 16$ & 0.000 & $97 \pm 1$ & 0.013 \\
\hline & \multirow[t]{3}{*}{ DMDM } & 20 & $-15 \pm 60$ & 0.223 & $75 \pm 4$ & 0.052 \\
\hline & & 40 & $44 \pm 38$ & 0.001 & $85 \pm 2$ & 0.029 \\
\hline & & 100 & $80 \pm 12$ & 0.000 & $88 \pm 3$ & 0.023 \\
\hline & \multirow[t]{3}{*}{ SMG } & 20 & $9 \pm 12$ & 0.582 & $83 \pm 6$ & 0.032 \\
\hline & & 40 & $34 \pm 8$ & 0.111 & $95 \pm 4$ & 0.015 \\
\hline & & 100 & $96 \pm 5$ & 0.000 & $100 \pm 1$ & 0.011 \\
\hline & \multirow[t]{3}{*}{$\mathrm{NT}$} & 20 & $20 \pm 4$ & 0.241 & $69 \pm 17$ & 0.073 \\
\hline & & 40 & $51 \pm 9$ & 0.017 & $2 \pm 57$ & 0.964 \\
\hline & & 100 & $62 \pm 1$ & 0.005 & $55 \pm 45$ & 0.144 \\
\hline & \multirow[t]{3}{*}{$N P$} & 20 & $52 \pm 7$ & 0.003 & $-5 \pm 35$ & 0.892 \\
\hline & & 40 & $44 \pm 24$ & 0.038 & $-59 \pm 57$ & 0.123 \\
\hline & & 100 & $60 \pm 36$ & 0.001 & $122 \pm 224$ & 0.002 \\
\hline \multirow[t]{12}{*}{ VRE } & \multirow[t]{3}{*}{ DAU } & 20 & $50 \pm 16$ & 0.000 & $68 \pm 25$ & 0.000 \\
\hline & & 40 & $64 \pm 29$ & 0.000 & $94 \pm 2$ & 0.000 \\
\hline & & 100 & $87 \pm 11$ & 0.000 & $98 \pm 3$ & 0.000 \\
\hline & \multirow[t]{3}{*}{ DMDM } & 20 & $-1 \pm 100$ & 0.925 & $25 \pm 15$ & 0.000 \\
\hline & & 40 & $62 \pm 15$ & 0.000 & $44 \pm 2$ & 0.000 \\
\hline & & 100 & $91 \pm 7$ & 0.000 & $85 \pm 2$ & 0.000 \\
\hline & \multirow[t]{3}{*}{ SMG } & 20 & $70 \pm 7$ & 0.001 & $61 \pm 2$ & 0.000 \\
\hline & & 40 & $73 \pm 7$ & 0.000 & $84 \pm 2$ & 0.000 \\
\hline & & 100 & $87 \pm 9$ & 0.000 & $93 \pm 2$ & 0.000 \\
\hline & \multirow[t]{3}{*}{ NT } & 20 & $17 \pm 6$ & 0.404 & $-5 \pm 12$ & 0.456 \\
\hline & & 40 & $-4 \pm 15$ & 0.856 & $7 \pm 2$ & 0.29 \\
\hline & & 100 & $-2 \pm 15$ & 0.902 & $18 \pm 5$ & 0.009 \\
\hline
\end{tabular}


Table 3 60- and 120-min incubation time experiment: Mean Kill Rates \pm SD of different compounds on five different bacterial strains and $p$ values ( $p^{*}$ compares 0 and the relevant dose of the same FAR for 60 min, $p^{* *}$ compares 0 and the relevant dose of each FAR for $120 \mathrm{~min}$ ) (Continued)

\begin{tabular}{|c|c|c|c|c|c|c|}
\hline \multirow{2}{*}{$\begin{array}{l}\text { Bacteria } \\
\text { strain }\end{array}$} & \multirow[t]{2}{*}{ Compound } & \multirow{2}{*}{$\begin{array}{l}\text { Concentration } \\
(\mathrm{mM})\end{array}$} & \multicolumn{2}{|l|}{$60 \mathrm{~min}$} & \multicolumn{2}{|l|}{$120 \mathrm{~min}$} \\
\hline & & & Mean Kill Rate \pm SD (\%) & $p^{*}$ & Mean Kill Rate \pm SD (\%) & $p^{* *}$ \\
\hline & NP & 20 & $-4 \pm 7$ & 0.798 & $65 \pm 16$ & 0.000 \\
\hline & & 40 & $-5 \pm 2$ & 0.750 & $34 \pm 15$ & 0.000 \\
\hline & & 100 & $-11 \pm 12$ & 0.517 & $48 \pm 31$ & 0.000 \\
\hline \multirow[t]{15}{*}{ PA } & DAU & 20 & $51 \pm 11$ & 0.000 & $19 \pm 18$ & 0.113 \\
\hline & & 40 & $67 \pm 10$ & 0.000 & $70 \pm 26$ & 0.000 \\
\hline & & 100 & $86 \pm 9$ & 0.000 & $99 \pm 1$ & 0.000 \\
\hline & DMDM & 20 & $64 \pm 33$ & 0.000 & $76 \pm 17$ & 0.000 \\
\hline & & 40 & $69 \pm 10$ & 0.000 & $16 \pm 37$ & 0.000 \\
\hline & & 100 & $79 \pm 12$ & 0.000 & $97 \pm 2$ & 0.000 \\
\hline & SMG & 20 & $61 \pm 3$ & 0.000 & $74 \pm 10$ & 0.000 \\
\hline & & 40 & $85 \pm 2$ & 0.000 & $89 \pm 9$ & 0.000 \\
\hline & & 100 & $96 \pm 3$ & 0.000 & $99 \pm 1$ & 0.000 \\
\hline & NT & 20 & $55 \pm 15$ & 0.000 & $7 \pm 15$ & 0.496 \\
\hline & & 40 & $83 \pm 3$ & 0.000 & $19 \pm 9$ & 0.112 \\
\hline & & 100 & $71 \pm 3$ & 0.000 & $24 \pm 28$ & 0.017 \\
\hline & NP & 20 & $70 \pm 7$ & 0.000 & $52 \pm 6$ & 0.000 \\
\hline & & 40 & $81 \pm 11$ & 0.000 & $78 \pm 5$ & 0.000 \\
\hline & & 100 & $83 \pm 5$ & 0.000 & $86 \pm 17$ & 0.000 \\
\hline \multirow[t]{15}{*}{ CA } & DAU & 20 & $24 \pm 4$ & 0.804 & $5 \pm 10$ & 0.290 \\
\hline & & 40 & $20 \pm 24$ & 0.846 & $7 \pm 8$ & 0.163 \\
\hline & & 100 & $72 \pm 10$ & 0.013 & $53 \pm 8$ & 0.000 \\
\hline & DMDM & 20 & $6 \pm 35$ & 0.585 & $23 \pm 10$ & 0.000 \\
\hline & & 40 & $42 \pm 14$ & 0.001 & $37 \pm 10$ & 0.000 \\
\hline & & 100 & $59 \pm 15$ & 0.000 & $60 \pm 11$ & 0.000 \\
\hline & SMG & 20 & $3 \pm 25$ & 0.274 & $0 \pm 3$ & 0.887 \\
\hline & & 40 & $33 \pm 21$ & 0.626 & $2 \pm 7$ & 0.627 \\
\hline & & 100 & $38 \pm 30$ & 0.430 & $4 \pm 4$ & 0.493 \\
\hline & NT & 20 & $16 \pm 11$ & 0.690 & $3 \pm 18$ & 0.525 \\
\hline & & 40 & $53 \pm 12$ & 0.109 & $1 \pm 5$ & 0.790 \\
\hline & & 100 & $42 \pm 3$ & 0.375 & $54 \pm 4$ & 0.000 \\
\hline & NP & 20 & $42 \pm 20$ & 0.333 & $0 \pm 8$ & 0.948 \\
\hline & & 40 & $25 \pm 2$ & 0.934 & $10 \pm 5$ & 0.049 \\
\hline & & 100 & $63 \pm 13$ & 0.039 & $86 \pm 4$ & 0.000 \\
\hline
\end{tabular}

less time and concentration dependence for SMG, which showed a reasonable kill rate even at the lowest concentration $(20 \mathrm{mM})$ and shortest time $(60 \mathrm{~min})$. A statistically significant $(p<0.01)$ bactericidal effect was noted for all concentrations of DAU, DMDM, and SMG against VRE although the effects were greatest with DAU and SMG. That being said, the effect with DMDM at $100 \mathrm{mM}$ for $60 \mathrm{~min}$ presented the most robust effect among all conditions (kill rate 91\%, $\mathrm{SD} \pm 7, p<0.0001$ compared to control group). Contrary to the aforementioned, the NAs NT and NP did not impair bacterial growth at all following a 60 min incubation (Table 3).

Pseudomonas aeruginosa $=$ PA (Fig. 1d and Table 3)

All FARs showed bactericidal effects against PA $(p<$ 0.0001 for each compound concentration compared to control group) in 60- and 120-min incubations, making PA the most susceptible of the strains tested to FARs. 


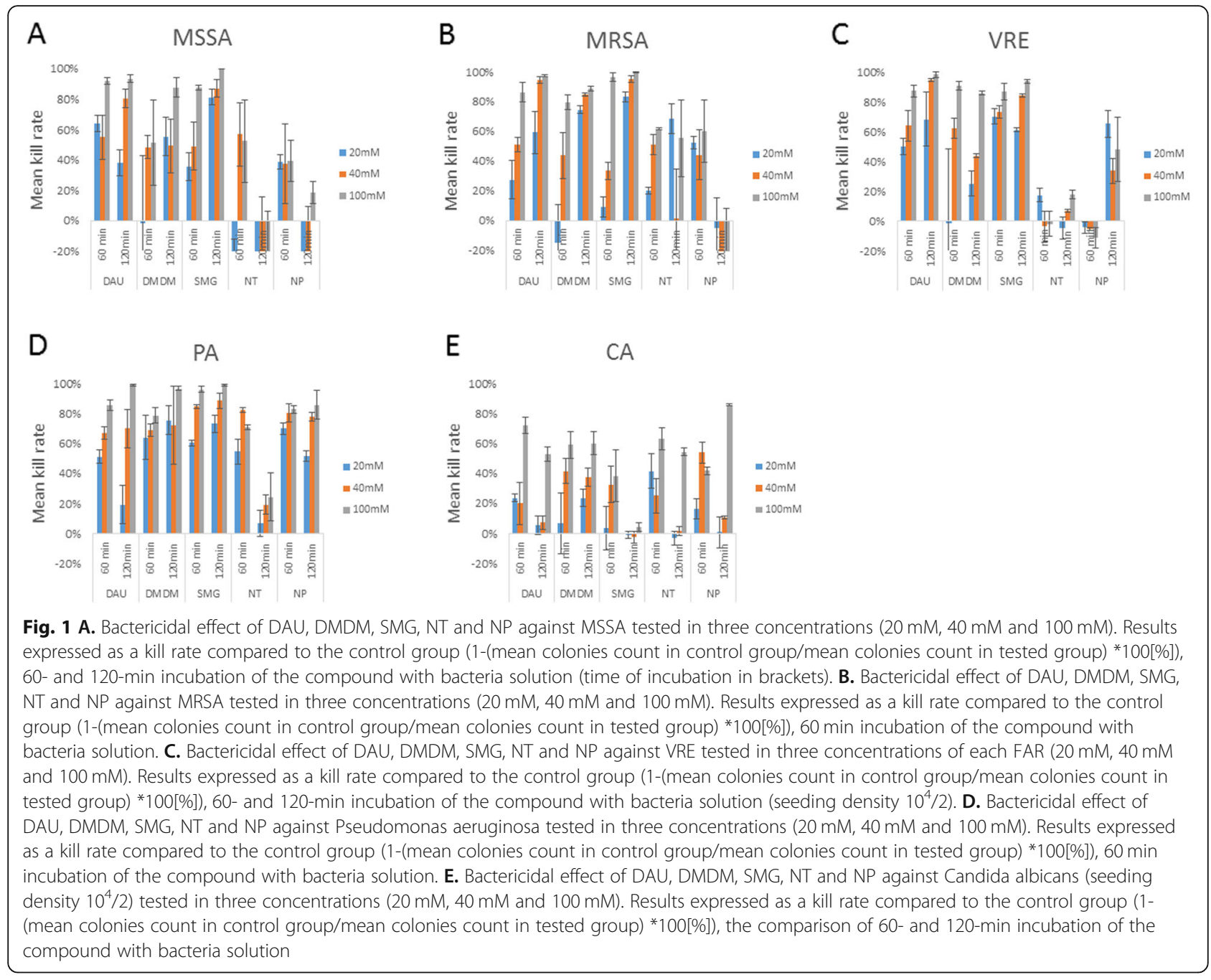

This is important as this was the only gram-negative rod tested and as such, represents one of an important group of bacteria (i.e. gram-negative rods) with several related species also showing antibiotic resistance, (i.e. being Klebsiella, E. coli, and Enterobacter). Furthermore, PA is becoming a major problem pathogen leading to rapid corneal perforation as a result of significant collagenase production. This makes cross-linking therapy with SMG an attractive possibility for preserving tissue, since crosslinking increases the resistance of the tissue collagen to enzymatic digestion. Future studies should examine the effects against specific pseudomonal strains.

SMG was the most effective FAR. The kill rate for SMG $100 \mathrm{mM}$ for a $60 \mathrm{~min}$ incubation was $96 \%$ (SD \pm 3 ) and $99 \%(\mathrm{SD} \pm 1)$ for $120 \mathrm{~min}$ incubations. That being said, at the lowest concentration $(20 \mathrm{mM})$, DMDM exerted stronger inhibition against PA than the equivalent concentration of SMG $(20 \mathrm{mM})$. For the majority of compounds, the results show high effectiveness of each compound at 60- and 120-min incubations, with the longer incubation time resulting in a stronger killing effect. However, there is one FAR (NT) that showed an opposite effect in this regard with decreased killing noted during the longer exposure time. The reason for this is unclear. However, one possibility is the reversibility of the reaction as well as products of the reaction getting involved in secondary reactions [26]. The data is displayed in Fig. 1 and Table 3.

\section{Candida albicans = CA (Fig. 1e and Table 3)}

Finally, CA growth was studied under the same time frame $(60,120 \mathrm{~min})$ as the previous strains of microorganisms. CA showed relative resistance to SMG, a compound with consistently good effects against the bacterial species. Although the average activity of FARs were generally lower for CA than for the bacteria strains, we did observe some trends of potential effects as follows: DAU $100 \mathrm{mM}$ at 60 and $120 \mathrm{~min}(p<0.0001)$, DMDM $20 \mathrm{mM}$ for $120 \mathrm{~min}(p<0.0001)$, DMDM 40 $\mathrm{mM}$ for 60 and $120 \mathrm{~min}(p<0.0001)$, DMDM $100 \mathrm{mM}$ 
for 60 and $120 \mathrm{~min}(p<0.0001)$, NT 20 and $100 \mathrm{mM}$ for 60 and $120 \mathrm{~min}(p<0.0001)$, NP $100 \mathrm{mM}$ for $120 \mathrm{~min}$ $(p<0.0001)$. The highest kill rate was obtained for NP $100 \mathrm{mM}$ for $120 \mathrm{~min}$ (kill rate $86 \%, \mathrm{SD} \pm 4, p<0.001$ ). In addition, it is interesting to note that the NAs performed better against CA than against the other bacteria tested. Figure 1e and Table 3 show the detailed information acquired in the CA experiments.

\section{Discussion}

The emergence of bacterial resistance to traditional antibiotics has become a serious problem in ophthalmology. The latest reports from India suggest that $80 \%$ of MRSA strains are resistant to available antibiotics, while the same is true for $20 \%$ of MSSA [34]. PA is known clinically as a rapid mutator that can lead to the development of extended spectrum B-lactamase producing variants (ESBL) $[35,36]$. New strategies are actively being sought in order to address this concern. One of them, riboflavin-UVA photochemical corneal cross-linking (CXL), has been studied for over a decade now. This procedure was initially used to induce cross-linking (CXL) to stabilize the cornea in keratoconus but is now actively being used to treat corneal infections (PACK$\mathrm{CXL}=$ photoactivated chromophore for keratitis-CXL). There are drawbacks, however, due primarily to the riboflavin photosensitizer and UVA light requirements (UVA risks include cataract formation and retinal degeneration, and direct keratocyte toxicity). CXL is also less effective in deep fungal corneal infections owing to a therapeutic cross-linking effect that is limited to the anterior stroma [37], and is contraindicated for herpetic keratitis, where exacerbations can occur [38, 39]. Therefore, to address these challenges, we are developing a topical approach using formaldehyde releasing compounds (FARs) with a goal of omitting UVA light exposure. In this study we evaluated the therapeutic effect of 5 FARs on 4 bacterial and 1 fungal strain.

The results indicate that different FARs have different microbicidal effects against the 5 pathogens tested. A summary of the results suggests that DAU, DMDM, and SMG all could be potentially used as Staphylococcus drugs (MRSA and MSSA). DAU and SMG, but less so DMDM, also showed promising effects on VRE and even at lower concentrations (20 mM, $40 \mathrm{mM})$.

Regarding the mechanism of the interaction between FARs and bacteria growth, it seems likely that the induced chemistry that is responsible for extracellular matrix modification could also cause microbial cytotoxicity. In our case, free FA released locally. FA is reactive and so it is likely that covalent modification of microbial target substrate molecules, including proteins with reactive groups (amines, tyrosine, cysteines, etc.), is central to the microbicidal effect [40].
DAU is an allantoin derivative, where allantoin reacts with four equivalents of formaldehyde under basic conditions to form the parent compound [41]. Thus, it has a theoretical yield of $4 \mathrm{~mol}$ of FA per mole of DAU. Dilution encourages the decomposition reaction, overcoming possible steric interference and facilitating the separation of the formaldehyde moiety from the mother compound. The actual FA yield of DAU is less than the expected 4 mol, however. Lehmann et al. demonstrated that DAU exists as a mixture of isomers, with "compound BHU" (1-(3,4-bis-hydroxymethyl-2,5-dioxo-imidazolidin-4-yl)1,3-bis-hydroxymethyl-urea) as the dominant form (30$40 \%$ ) [42]. It is hypothesized that the remainder consists of many polymers of allantoin-formaldehyde condensation products. Thus, this complex mixture of compounds could account for the lower than expected FA yield.

DMDM is a hydantoin with a theoretical yield of two FA moieties. For DMDM at concentrations from $\sim 3$ $\mathrm{mM}$ to $\sim 1.3 \mathrm{M}$ a more alkaline $\mathrm{pH}$ (8.5-9 as compared to $\mathrm{pH}$ 6-6.5 and $\mathrm{pH} 4-4.5)$ and a lower concentration favored higher levels of free FA, consistent with the release characteristics of DAU, which is also increased at lower concentrations [43]. Once FA is liberated from either of the nitrogen atoms of the five-membered ring, the resulting negative charge on the nitrogen atom is delocalized into the $\pi$-system provided by both of the adjacent carbonyl moieties. The formation of intramolecular hydrogen bonds between local DMDM molecules stabilizes any additional negative charge.

SMG has a theoretical yield of one mole of FA per mole of SMG. In spite of this lower ratio when compared to the other FARs of this study, SMG appears to release FA more readily than other FARs with strong tissue cross-linking effects [25] and behaves differently from the other FARs in certain regards. Solutions of SMG in water tend to be highly alkaline (Fig. 1) but can be modulated downward with the addition dilute neutral buffers. The other FARs produce neutral solutions and the FA release can be facilitated by the addition of base [44]. It has a molecular weight of $127.07 \mathrm{~g} / \mathrm{mol}$. Its small size facilitates its ability to pass through the epithelial barrier to induce cross-linking. In aqueous solutions, SMG decomposes entirely to formaldehyde and its parent compound, sodium glycinate, which is not considered harmful [45].

FARs do not tend to induce microbial resistance in the same manner as traditional antibiotics albeit resistance can occur. A review of this topic has been previously published [46]. Furthermore, because they are broadspectrum agents, these agents could have unique efficacy against emerging pathogens such as MRSA, VRE, and extended beta-lactamase (EBL)-resistant strains of Pseudomonas. Of note, there is precedent for using 
broad spectrum anti-septic agents such as these for treating infectious keratitis. Human trials indicate that antiseptic agents can be used topically for the treatment of infected tissue fields [46]. Chlorhexidine has been used for Acanthameoba, Staphylococcus aureus and Pseudomonas aeruginosa keratitis [47], iodine for fungal keratitis [48], and hypochlorous acid has been used for infected wounds [49, 50]. Developing single broadspectrum agents that could take the place of multi-agent therapy for infectious keratitis could be of great patient benefit and is the driving force behind these studies.

Finally, this study only considers direct microbicidal effects and does not account for the potential effects upon the extracellular matrix that induce a resistance to enzymatic digestion. Thus, it is difficult to predict which agents will be most effective in vivo, since different FARs have different protein cross-linking capabilities, in addition to the direct microbicidal effects. Another study limitations are of our concern: FAR toxicity [25], interaction between FARs and other topical drugs, risk of a scar formation. Once again, we emphasize that this is an in vitro study and the effects and considerations for in vivo use can be very different. That being said, these studies do serve as an initial guide to further development and should prompt the testing of these compounds in live animal studies. The results of such future studies hold the promise of significantly increasing our armamentarium against threatening infections caused by highly resistant micro-organisms.

\section{Conclusions}

Our results show that each FAR compound has different effects against different cultures, including antibiotic resistant strains such as MRSA, VRE, and pseudomonas. Thus, the clinically useful antimicrobial armamentarium could be broadened by the addition of DAU, DMDM, SMG and other FARs. These agents could be particularly helpful for treating antibiotic-resistant tissue infections of the cornea (i.e. infectious keratitis) as well as other types of tissue infections. Further testing in live animal models are indicated, as well as trials of compassionate human use.

\begin{abstract}
Abbreviations
BSA: Bovine Serum Albumin; CA: Candida albicans; CFU: colony-formulating units; CXL: UVA-riboflavin mediated photochemical cross-linking (also known as the Dresden protocol); DAU: Diazolidinyl urea; DMDM: 1,3Bis(Hydroxymethyl)-5,5-dimethylimidazolidine-2,4-dione; FA: Formaldehyde; FAR(s): Formaldehyde releasing agent(s); MDR: Multi-drug resistant; MRSA: Methicillin-resistant Staphylococcus aureus; MSSA: Methicillin-sensitive Staphylococcus aureus; NP: 2-nitro-1-propanol; NT: 2-(hydroxymethyl)-2-nitro1,3-propanediol = nitrotriol; PA: Pseudomonas aeruginosa; SMG: Sodium hydroxymethylglycinate; TXL: Therapeutic tissue cross-linking;

UVA: Ultraviolet-A irradiation; VRE: Vancomycin Resistant Enterococcus
\end{abstract}

\section{Acknowledgments}

The authors wish to thank Dr. Shanta Modak of Columbia University for her guidance and for providing pathogen strain materials; and Mr. Jimmy Duong from the Design and Biostatistics Resource of the Biostatistical Core Facility of the Irving Institute at Columbia University Medical Center for biostatistical consultation. Joanna Przybek-Skrzypecka wishes to thank the Kościuszko Foundation for a research travel grant to study in the U.S. at Columbia University.

\section{Authors' contributions}

DEA contributed to data acquisition/analysis and manuscript drafting. JP-S contributed to data acquisition/analysis and manuscript drafting. She was also primarily responsibility for manuscript revisions and resubmissions. MZ contributed to data acquisition/analysis and manuscript revisions. AT contributed to data acquisition/analysis. LHS contributed to study conception/design. TN contributed to study conception and data interpretation. SLT contributed to study conception and manuscript drafting. DCP was primarily responsible for study conception/design, data interpretation, and manuscript drafting/revision. All authors have read and approved the manuscript.

\section{Author information}

David C. Paik, M.D. is an Associate Professor of Ophthalmic Science in the Department of Ophthalmology at Columbia University Medical Center. He is the Director of the Laboratory for Tissue Cross-linking and the Principal Investigator of $\mathrm{NIH}$-funded research that aims to develop therapeutic tissue crosslinking as a novel method for strengthening weakened tissue, particularly of the cornea and sclera. He has also served on NIH study sections related to anterior segment ocular research.

\section{Funding}

The study design, data collection, analysis, interpretation of the data, and writing of the manuscript were supported in part by the following: Research to Prevent Blindness (data collection) and by National Institutes of Health Grants NEl R01EY020495 (all parts of the study design, data collection, analysis, interpretation and writing), NEI P30 EY019007 (statistical support and research infrastructure), and NCRR UL1RR024156 (statistical support).

\section{Availability of data and materials}

The datasets used and analyzed during the current study are available from the corresponding author on reasonable request.

Ethics approval and consent to participate Not applicable.

\section{Consent for publication}

Not applicable.

\section{Competing interests}

The authors declare that they have no competing interests.

\section{Author details}

${ }^{1}$ Department of Ophthalmology, Edward S. Harkness Eye Institute, Columbia University College of Physicians and Surgeons, 635 West 165th Street, Research Annex Room 715, New York, NY 10032, USA. ²Department of Experimental and Clinical Pharmacology, Medical University of Warsaw, Warsaw, Poland. ${ }^{3}$ Department of Ophthalmology, Medical University of Warsaw, Warsaw, Poland.

Received: 15 April 2019 Accepted: 3 January 2020

Published online: 15 January 2020

\section{References}

1. Tacconelli E, Magrini N. Global Priority List of Antibiotic-Resistant Bacteria to Guide Research, Discovery, and Development of New Antibiotics: World Health Organization; 2017. Available online: https://www.who.int/medicines/ publications/global-priority-list-antibiotic-resistant-bacteria/en/.

2. Cornea/external disease summary benchmarks for preferred practice pattern guidelines: American Academy of Ophthalmology; 2017. Available online: https://www.aao.org/Assets/7c7cc42a-675c-41ee-ba61-fa113c271c43/6364 92185326530000/bc-2208-pppsummarybenchmarks-17-cornea-pdf.

3. Austin A, Lietman T, Rose-Nussbaumer J. Update on the Management of Infectious Keratitis. Ophthalmol. 2017;124:1678-89. 
4. Eurosurveillance editorial team C. CDC publishes report on antibiotic resistance threats in the United States for the first time. Eurosurveillance. 2013;18:20588

5. Teweldemedhin M, Gebreyesus $H$, Atsbaha AH, Asgedom SW, Saravanan M. Bacterial profile of ocular infections: a systematic review. BMC Ophthalmol. 2017;17:212

6. Peng MY, Cevallos V, McLeod SD, Lietman TM, Rose-Nussbaumer J. Bacterial keratitis: isolated organisms and antibiotic resistance patterns in San Francisco. Cornea. 2018:37:84-7.

7. Shalchi Z, Gurbaxani A, Baker M, Nash J. Antibiotic resistance in microbial keratitis: ten-year experience of corneal scrapes in the United Kingdom. Ophthalmol. 2011;118:2161-5.

8. Drug Resistance in Infectious Agents. A Global Threat to Humanity. GSCIENCE ACADEMIES STATEMENTS; 2013. p. 2013.

9. Parmar A, Lakshminarayanan R, lyer A, et al. Design and syntheses of highly potent Teixobactin analogues against Staphylococcus aureus, methicillinresistant Staphylococcus aureus (MRSA), and Vancomycin-resistant enterococci (VRE) in vitro and in vivo. J Med Chem. 2018;61:2009-17.

10. Joseph MR, Al-Hakami AM, Assiry MM, et al. In vitro anti-yeast activity of chloramphenicol: a preliminary report. J Mycol Med. 2015;25:17-22.

11. Blanco AR, Nostro A, D'Angelo V, D'Arrigo M, Mazzone MG, Marino A. Efficacy of a fixed combination of tetracycline, chloramphenicol, and Colistimethate sodium for treatment of Candida albicans keratitis. Invest Ophthalmol Vis Sci. 2017;58:4292-8

12. Spierer O, Miller D, O'Brien TP. Comparative activity of antimicrobials against Pseudomonas aeruginosa, Achromobacter xylosoxidans and Stenotrophomonas maltophilia keratitis isolates. Br J Ophthalmol. 2018;102: 708-12.

13. Zabawa TP, Pucci MJ, Parr TR Jr, Lister T. Treatment of gram-negative bacterial infections by potentiation of antibiotics. Curr Opin Microbiol. 2016; 33:7-12.

14. Coskunseven E, Jankov MR 2nd, Hafezi F. Contralateral eye study of corneal collagen cross-linking with riboflavin and UVA irradiation in patients with keratoconus. J Refract Surg. 2009;25:371-6.

15. Hafezi F, Kanellopoulos J, Wiltfang R, Seiler T. Corneal collagen crosslinking with riboflavin and ultraviolet a to treat induced keratectasia after laser in situ keratomileusis. J Cataract Refract Surg. 2007;33:2035-40.

16. Hafezi F. Significant visual increase following infectious keratitis after collagen cross-linking. J Refract Surg. 2012;28:587-8.

17. Makdoumi K, Backman A. Photodynamic UVA-riboflavin bacterial elimination in antibiotic-resistant bacteria. Clin Exp Ophthalmol. 2016;44:582-6.

18. Said DG, Elalfy MS, Gatzioufas Z, et al. Collagen cross-linking with Photoactivated riboflavin (PACK-CXL) for the treatment of advanced infectious keratitis with corneal melting. Ophthalmol. 2014;121:1377-82.

19. Price MO, Tenkman LR, Schrier A, Fairchild KM, Trokel SL, Price FW Jr. Photoactivated riboflavin treatment of infectious keratitis using collagen cross-linking technology. J Refract Surg. 2012;28:706-13.

20. Makdoumi K, Mortensen J, Sorkhabi O, Malmvall BE, Crafoord S. UVAriboflavin photochemical therapy of bacterial keratitis: a pilot study. Graefes Arch Clin Exp Ophthalmol. 2012;250:95-102.

21. Kymionis GD, Kouroupaki Al, Liakopoulos DA, Arandjelovic IR, Tsoulnaras KI. Multiorganism, drug-resistant keratitis treated by corneal crosslinking. Eur J Ophthalmol 2016:26:0

22. Chan TC, Lau TW, Lee JW, Wong IY, Jhanji V, Wong RL. Corneal collagen cross-linking for infectious keratitis: an update of clinical studies. Acta Ophthalmol. 2015;93:689-96.

23. Papaioannou L, Miligkos M, Papathanassiou M. Corneal collagen crosslinking for infectious keratitis: a systematic review and meta-analysis Cornea. 2016:35:62-71.

24. Uddaraju M, Mascarenhas J, Das MR, et al. Corneal cross-linking as an adjuvant therapy in the Management of Recalcitrant Deep Stromal Fungal Keratitis: a randomized trial. Am J Ophthalmol. 2015;160:131-4 e135.

25. Babar N, Kim M, Cao K, et al. Cosmetic preservatives as therapeutic corneal and scleral tissue cross-linking agents. Invest Ophthalmol Vis Sci. 2015;56: 1274-82.

26. Paik DC, Solomon MR, Wen Q, Turro NJ, Trokel SL. Aliphatic betanitroalcohols for therapeutic corneoscleral cross-linking: chemical mechanisms and higher order nitroalcohols. Invest Ophthalmol Vis Sci. 2010;51:836-43

27. SciFinder. Chemical Abstracts Service.

28. Sigma-Aldrich. Diazolidinyl urea [Material Safety Data Sheet].
29. ACME-Hardesty C. DMDM hydantoin [Material safety data sheet].

30. Isenberg SJ, Apt L, Valenton M, Sharma S, Garg P, Thomas PA, Parmar P, Kaliamurthy J, Reyes JM, Ong D, Christenson PD, Del Signore M, Holland GN. Prospective, Randomized Clinical Trial of Povidone-lodine 1.25\% Solution Versus Topical Antibiotics for Treatment of Bacterial Keratitis. Am J Ophthalmol. 2017;176:244-53.

31. Sigma-Aldrich. Sodium hydroxymethylglycinate [Material Safety Data Sheet].

32. Products IS. Sodium hydroxymethylglycinate [Material Safety Data Sheet].

33. Rapuano PB, Scanameo AH, Amponin DE, et al. Antimicrobial studies using the therapeutic tissue cross-linking agent, sodium Hydroxymethylglycinate: implication for treating infectious keratitis. Invest Ophthalmol Vis Sci. 2018; 59:332-7.

34. Lalitha P, Manoharan G, Karpagam R, et al. Trends in antibiotic resistance in bacterial keratitis isolates from South India. Br J Ophthalmol. 2017;101:108-13.

35. Weldhagen GF, Poirel L, Nordmann P. Ambler class a extended-spectrum beta-lactamases in Pseudomonas aeruginosa: novel developments and clinical impact. Antimicrob Agents Chemother. 2003;47:2385-92.

36. Sacha P, Wieczorek P, Hauschild T, Zorawski M, Olszanska D, Tryniszewska E. Metallo-beta-lactamases of Pseudomonas aeruginosa--a novel mechanism resistance to beta-lactam antibiotics. Folia Histochem Cytobiol. 2008;46:137-42.

37. Dias J, Diakonis VF, Kankariya VP, Yoo SH, Ziebarth NM. Anterior and posterior corneal stroma elasticity after corneal collagen crosslinking treatment. Exp Eye Res. 2013;116:58-62.

38. Perna JJ, Mannix ML, Rooney JF, Notkins AL, Straus SE. Reactivation of latent herpes simplex virus infection by ultraviolet light: a human model. J Am Acad Dermatol. 1987:17:473-8.

39. Rooney JF, Straus SE, Mannix ML, Wohlenberg CR, Banks S, Jagannath S Brauer JE, Notkins AL. UV light-induced reactivation of herpes simplex virus type 2 and prevention by acyclovir. J Infect Dis. 1992;166:500-6.

40. Conaway CC, Whysner J, Verna LK, Williams GM. Formaldehyde mechanistic data and risk assessment: endogenous protection from DNA adduct formation. Pharmacol Ther. 1996;71:29-55.

41. Flyvholm MA. Preservatives in registered chemical products. Contact Dermatitis. 2005;53:27-32.

42. Lehmann SV, Hoeck U, Breinholdt J, Olsen CE, Kreilgaard B. Characterization and chemistry of imidazolidinyl urea and diazolidinyl urea. Contact Dermatitis. 2006;54:50-8.

43. Emeis D, Anker W, Wittern KP. Quantitative 13C NMR spectroscopic studies on the equilibrium of formaldehyde with its releasing cosmetic preservatives. Anal Chem. 2007;79:2096-100

44. Solomon MR, O'Connor NA, Paik DC, Turro NJ. Nitroalcohol induced hydrogel formation in amine-functionalized polymers. J Appl Polym Sci. 2010;117:1193-6.

45. The Scientific Committee on Costmetic Products and Non-Food Products Intended for Consumers. Opinion concerning the determination of certain formaldehyde releasers in cosmetic products. SCCNFP 2002. Available online: https://webcache.googleusercontent.com/search?q=cache:3 dOLXqYJQvgJ:https://ec.europa.eu/health/archive/ph_risk/committees/sccp/ documents/out188_en.pdf+\&cd=1\&hl=pl\&ct=clnk\&gl=pl\&client=safari.

46. McDonnell G, Russell AD. Antiseptics and disinfectants: activity, action, and resistance. Clin Microbiol Rev. 1999;12(1):147-79.

47. Bu P, Riske PS, Zaya NE, Carey R, Bouchard CS. A comparison of topical chlorhexidine, ciprofloxacin, and fortified tobramycin/cefazolin in rabbit models of Staphylococcus and Pseudomonas keratitis. J Ocul Pharmacol Ther. 2007;23(3):213-20.

48. Isenberg SJ, Apt L, Valenton M, et al. Prospective, randomized clinical trial of Povidone-iodine $1.25 \%$ solution versus topical antibiotics for treatment of bacterial keratitis. Am J Ophthalmol. 2017;176:244-53.

49. Robson MC, Payne WG, Ko F, Mentis M, Donati G, Shafii SM, Culverhouse S, Wang L, Khosrovi B, Najafi R, Cooper DM, Bassiri M. Hypochlorous acid as a potential wound care agent: part II Stabilized Hypochlorous Acid: Its Role in Decreasing Tissue Bacterial Bioburden and Overcoming the Inhibition of Infection on Wound Healing. J Burns Wounds. 2007;6:e6.

50. Odorcic S, Haas W, Gilmore MS, Dohlman CH. Fungal infections after Boston type 1 Keratoprosthesis implantation: literature review and in vitro antifungal activity of Hypochlorous acid. Cornea. 2015;34(12):1599-605.

\section{Publisher's Note}

Springer Nature remains neutral with regard to jurisdictional claims in published maps and institutional affiliations. 